\title{
“My Picture is About Opening Up Students' Minds Beyond School Gates!" School Principals' Perceptions of STEM Learning Environments
}

\author{
Vesife Hatisaru $^{\mathrm{a}}$ (iD), Sharon Fraser ${ }^{\mathrm{a}}$ iD, Kim Beswick ${ }^{\mathrm{b}}$ iD \\ ${ }^{a}$ University of Tasmania, Australia; ${ }^{b}$ University of New South Wales, Australia
}

\begin{abstract}
The provision of effective leadership in STEM education is essential to support teachers to consider approaches to STEM and to carry them out effectively. Principals' perceptions of STEM teaching and learning are, therefore, significant. In this paper we report on the perceptions of 21 primary and secondary school principals through their completion of the Draw a STEM Learning Environment Test (D-STEM), assessed through a customised rubric. Findings revealed that the participant principals maintained a diversity of interpretations of STEM learning environments primarily equated to the use of student-centred pedagogies in classrooms. Very few responses depicted and/or described teaching and learning practices anchored in realistic problems, which can enable the integration of individual STEM disciplines, and engage students in the translation of concepts across multiple representations. The use of representational tools remained implicit or was absent in most of the responses. Findings are discussed along with methodological issues, and implications and future research directions are suggested.
\end{abstract}

Keywords: STEM learning environments, school principals, drawings, STEM education

\section{Introduction}

In Australia and internationally there is growing demand for graduates in science, technology, engineering and mathematics (STEM disciplines) to contribute to economic prosperity and productivity (Atkinson \& Mayo, 2010; Office of the Chief Scientist, 2012; Science and Technology Policy Division of the OECD Directorate for Science, Technology and Innovation, 2016). Enrolments in senior secondary mathematics courses that prepare students for university studies in STEM fields, yet, have been declining (Australian Academy of Science, 2016; Barrington \& Evans, 2014; Wienk, 2017). School students who are motivated towards and interested in STEM subjects are more likely to pursue STEM related careers (Stohlmann, Moore, \& Roehrig, 2012). Enhancing the teaching of STEM subjects is therefore a priority. Research in STEM education field has grown, but there are several practical challenges to implementing effective STEM teaching and learning. Effective teaching of STEM, for instance, requires close collaboration among teachers, the commitment of teachers involved, and professional learning and administrative support (Zubrowski, 2002).

Although there has been little attention paid, to date, to the role that school principals might play in enhancing STEM teaching and learning (Likourezos, Beswick, Geiger, \& Fraser, 2020), and hence supporting increased enrolments in STEM subjects, there is a substantial body of research on

${ }^{1}$ Corresponding author: Vesife Hatisaru, University of Tasmania, College of Arts, Law and Education, Faculty of Education, TAS 7248 Launceston, Email: vesife.hatisaru@utas.edu.au

Hatisaru, V., Fraser, S., \& Beswick, K. (2020). “My picture is about opening up students' minds beyond school gates!” School principals' perceptions of STEM learning environments. Journal of Research in STEM Education, 6(1), 18-38. 
principals' instructional leadership (Aas \& Paulsen, 2019; Robinson, 2007). From this work we know that school leaders have more influence on teaching practice when they are involved in the design and implementation of curriculum (Pietsch \& Tulowitzki, 2017), and are more likely to influence student outcomes when the teaching and learning that happen in their schools is the central focus of their work (Robinson, 2007). It is reasonable to assume that these general findings apply also to STEM, and that the role that principals play in enhancing STEM teaching and learning would be dependent upon, among other things, the ways in which they believe STEM subjects should be taught and are best learned. In this study, therefore, we address the question: What are school principals' perceptions of STEM learning environments?

In doing so, this paper contributes to understanding the bases of instructional leadership in relation to STEM and presents implications for the kinds of supports that school leaders might need in order to build their capacity to exercise instructional leadership in this area. A further contribution is methodological and addresses the question: How can established drawing-based techniques be adapted as a way of uncovering principals' perceptions of STEM learning environments? In the sections that follow we review literature on STEM learning environments, including the principal's role in creating and maintaining them, and consider what is known about the use of drawings to study perceptions of learning environments.

We use the term learning environment as the diverse physical location, context and culture in which teaching and learning take place. Evans, Harvey, Buckley and Yan (2009) suggested three complementary components of a learning environment: (1) academic (the pedagogical and curricular elements); (2) management (the discipline styles for maintaining order); and (3) emotional (the affective interactions within the classroom). In this study, we focus on the first component, the pedagogical and curricular elements of the STEM learning environments. Importantly perceptions as to these components are likely to differ according to the participant in the environment who is consulted. That is, the teacher and individual students in a class may all have different perceptions of what goes on in the same learning environment (Beswick, 2007). Similarly, principals' perceptions are likely to be unique and hence worthy of particular study.

\section{STEM Learning Environments}

The acronym, STEM, is interpreted in a variety of ways and there is considerable confusion among what it means in school education (Bybee, 2010). It is used to refer to each of the four component disciplines - Science, Technology, Engineering, and Mathematics - separately, and also to the integrated teaching of two or more of them (Hobbs, Clark, \& Plant, 2018). In this study, as in the larger project of which it is part, we did not mandate any specific conception of STEM teaching and learning or of STEM learning environments. Rather, we were interested in how our participants perceived these things. We used the literature on effective STEM teaching and learning to frame our analysis of participants' responses.

\section{STEM Integration}

When considered in terms of discretely taught disciplines, STEM has been interpreted as an impetus to enhance the teaching of the individual disciplines including by adopting approaches to teaching similar to those advocated by proponents of integrated STEM, such as the use of challenging problem in mathematics (Hobbs et al., 2018). When used in an integrated sense, STEM is often associated with pedagogical approaches such as inquiry or problem-based learning which have long been advocated for by science (e.g. Driver, Newton, \& Osborne, 2000) and mathematics (e.g. Schroeder \& Lester, 1989) education researchers. According to Kennedy and Odell (2014), effective STEM education requires teachers to move away from traditional one-way, direct instruction teaching practices to towards instructional strategies that better motivate students and support their learning. Hobbs et al. (2018) identified "skills and proficiencies that are common to STEM disciplines" (p. 142) along with pedagogies and practices. Namely, inquiry using multiple representations, problem-solving, design-based approaches and the incorporation of digital technologies, in their view, are essential to a program being a STEM program. Similarly, in their study of STEM education researchers' perceptions of STEM learning environments, Hatisaru, Beswick and Fraser (2019) found 
evidence that some participants seemed to equate STEM teaching and learning with pedagogies that involved group work.

In many countries, including Australia, teachers must report on individual STEM disciplines and this contributes to variation in the extent to which STEM subjects are integrated in schools (Timms, Moyle, Weldon, \& Mitchell, 2018). Hobbs et al. (2018), for example, described five ways in which STEM was operationalised in the schools with which they worked. These were: (1) enhanced but separate teaching of the four disciplines; (2) teaching the four disciplines but with two emphasised and integrated; (3) integrating one discipline into the other three that are separately taught; (4) complete integration of the four disciplines by a single teacher; and (5) teaching integrated STEM but with individual and distinct contributions from teachers of the four disciplines. Hobbs et al. (2018) maintained that, by focussing on STEM pedagogies and practices, in any of these models, learning experiences can be created that are engaging for students and that maximise student learning through linking relevant concepts and processes from the individual STEM disciplines. Vasquez et al. (2013) also identified a set of practices inherent in the individual disciplines of science and engineering, technology, and mathematics that can support and strengthen each other in STEM teaching. Their list included asking questions, defining problems, developing and using models, planning and carrying out investigations, analysing and interpreting data, using mathematics and computational thinking, constructing explanations and designing solutions, engaging in argument from evidence, and evaluating and communicating information. Vasquez et al. (2013) argued that these practices represent the capabilities that students are expected to gain in their years of schooling and that they are essential in today's knowledge-based and technological society.

Glancy and Moore (2014) presented a theoretical case for effective STEM classes being characterised by the integration of the four STEM subjects. They argued that "separating the disciplines sets up artificial divides that are not generally present outside of the classroom, while integration presents the disciplines in a more honest or realistic fashion" (p. 4). Similarly, Vasquez et al. (2013) argued that effective STEM teaching requires genuine connections to be made between subjects. They argued that this can lead to enhanced conceptual understanding as students apply their learning from individual STEM subjects. Part of this is understanding disciplinary representations, and sharing and communicating their understandings, enhances students' professional discourse proficiency (Vasquez et al., 2013).

Implicit in these arguments is that students study individual STEM subjects, or study them alongside integrated STEM. There is relative silence from STEM education researchers who advocate for integrated STEM teaching, on whether, how, and which, individual STEM subjects should be taught, beyond Hobbs et al.'s (2018) acknowledgement that current curricula considerations mean that the nature and extent of integration varies. Focussing on STEM as pedagogy avoids these questions to the extent that the practices advocated (e.g. by Hobbs et al., 2018 and Vasquez et al., 2013) can be applied to individual disciplines or in the context of any variant of integration. This fact can, of course, be used to argue against the imperative of integration.

\section{Solving STEM Problems}

According to Glancy and Moore (2014), STEM problems are ideally grounded in the real world; they are problems that are experienced by the community. Although students may draw upon subject knowledge of separate STEM disciplines, the problems are interdisciplinary. When problems arise from the local community context, students can relate to, engage with, and makes sense of them based on their own experiences (Glancy \& Moore, 2014). A further benefit of working on real world problems is that students can see STEM as it is practised (Hobbs et al., 2018). In line with this, rather than being a solitary activity, solving STEM problems is necessarily collaborative. As in the real world, students work together and take on specific roles and responsibilities as interdisciplinary problems are tackled by teams consisting of members with differing knowledge and expertise (Glancy \& Moore, 2014). In addition, students develop their understanding of the nature of evidence in different contexts through collecting data, using evidence to justify a solution or a decision, and making judgments about the reliability of the information they use or generate 
(Vasquez et al., 2013). In these sorts of environments teachers take on roles other than knowledge giver, including those of facilitator or guide, collaborator and learner (Crawford, 2000). Students take ownership of their learning and are active, taking on roles other than listener or knowledge receiver, such as those of collaborator, planner and experimenter (Crawford, 2000).

At the heart of the STEM practices proposed by Vasquez et al. (2013) and Hobbs et al. (2018) is the provision of opportunities for students to develop and interrogate their ideas. The conceptual, digital, and physical tools that teachers use in STEM classrooms are essential to learning that provides these opportunities. They might be representational and include graphs, maps, diagrams and tables (Goos, Geiger, \& Dole, 2014); technologies that facilitate modelling or simulations (Kennedy \& Odell, 2014), digital technologies (Hobbs et al., 2018), or physical tools such as those used in construction (e.g. saws, measuring devices, hammers), electronic materials (e.g. computers, design programs, robotics kits, calculators), and materials used in design (e.g. wood, cardboard, construction paper, glue) (Stohlmann et al., 2012). Students draw upon and develop their skills in using these tools as they collaboratively engage in a STEM inquiry, problem solution, or project. Finally, to facilitate concept development, generalization and abstraction, Glancy and Moore (2014) recommended that in STEM classrooms concepts be presented using multiple types of representations (written symbols, pictorial representations, real life situations, verbal symbols, and concrete representations or manipulatives), with the problems structured to require translations among these representational modes.

The proposed components of effective STEM teaching and learning environments described above, in fact, have been promoted for several decades as optimal ways of teaching both mathematics and science. For example, Pape and Tchoshanov (2001) discussed the importance of using multiple representations in mathematics in order to develop students' conceptual understanding. Many others, following social constructivist theories of learning, promoted collaboration among students. For mathematics, these sorts of approaches have central to reform movements in mathematics since the 1980s. They were, for example, promoted by the National Council of Teachers of Mathematics (NCTM) in their 1989 principles and standards and in subsequent updates of that internationally influential work (e.g. NCTM, 2000) and curricula that have embraced these principles to varying degrees (e.g. Common Core State Standards for Mathematics in the US, the Australian Curriculum: Mathematics in Australia (Australian Curriculum, Assessment and Reporting Authority)). More recently the NCTM (2014) have recommended that teaching and learning of mathematics includes using and connecting mathematical representations. The important difference between these subject specific attempts to reform teaching and more recent calls for integrated STEM teaching, could be that inherently interdisciplinary problems demand or require these kinds of practices or, at the very least, integrated STEM provides an impetus for promoting teaching and learning practices known to be effective in individual STEM subjects. At least in mathematics, calls for reformed pedagogy have achieved insufficient traction (Roesken, Pepin, \& Törner, 2011).

\section{The Role of Principals in STEM Teaching and Learning}

Research on instructional leadership, not necessarily related to specific school subjects, has established that principals can positively influence student learning outcomes by enhancing the quality of teaching (Pietsch \& Tulowitzki, 2017). We also know that transformational leadership styles allow principals to establish school environments in which teachers are motivated and inclined to be innovative in their pedagogy (Pietsch \& Tulowitzki, 2017). It is reasonable to assume, therefore, that principals are key to instigating, supporting and sustaining the kinds of STEM learning environments described in the previous section. Also pertinent is Tulowitzki's (2019) finding that principals require professional development to build their capacity to respond to changing school and national priorities and aspirations, such as the recent and ongoing impetus to enhance STEM teaching and learning.

Some researchers have reported findings related to instructional leadership of individual STEM disciplines and noted a tendency for principals not to lead on instruction in science and technology (e.g. Gerard, Bowyer, \& Linn, 2008). Similarly, Carpenter and Peake (2013) highlighted principals' relative lack of confidence in relation to their ability to provide instructional leadership in 
mathematics. Nevertheless, principals can exercise instructional leadership by facilitating teachers' contributions to decision making with an environment characterised by trust (Smetana, Wenner, Settlage, \& McCoach, 2016). That is, deferring to the knowledge of specialist STEM teachers can be seen as an important part of principals' instructional leadership. In relation to science, Lewthwaite (2004) advocated instructional leadership in the form of establishing a coherent strategy for curriculum improvement that recognises the relationship between curricula and learning environments. Gerard et al. (2008) urged principals to consider the ways in which new curricula fit with their particular school goals, existing programs, and community connections. In the context of mathematics, Nelson (2010) described Leadership Content Knowledge (LCK) as comprising principals' knowledge of the subject matter and their beliefs about how it is learned and most effectively taught.

The ways in which principals perceive effective STEM learning environments is relevant to their capabilities and to the nature of the specific support that principals might need to enhance the STEM culture of their schools and support teachers to optimise the STEM learning environments that they create for students. In the next section, we turn to the methodological issues associated with researching perceptions of STEM learning environments that participant school principals held.

\section{Perceptions of STEM Learning Environments}

Learning environments research "provides one approach for conceptualizing, assessing, investigating, and improving what goes on in classrooms" (Fraser, 2014, p. 104). Although questionnaires have been used in learning environment research for some time, "there is considerable scope for the development of new methods and the wider use of established methods for qualitative studies" (Fraser, 2014, p. 116). In this study, we used drawings as well as writing as a mechanism for collecting information from the study sample.

\section{Using Drawings to Study Learning Environments}

There is a growing body of literature on the use of image-based methods in qualitative research (Matthews, 2012). One such method, using a particular image-based method, 'drawings', has been found to be a valid indicator of perceptions of classroom environments (Haney, Russell, \& Bebell, 2004). Scientific interest in individual's drawings dates from the 1900s, with the drawings having been used in psychology, anthropology and ethnology (e.g. Goodenough, 1926) as well as in education research (e.g. Chambers, 1983). As a result, literature focusing on the use of drawings for research is extensive; our purpose here is to present a brief snapshot of the literature relevant to individual's perceptions in relation to the individual STEM subjects.

The research capturing students' perceptions on science education through drawings arose in mid-1950s, after the seminal work of Mead and Métraux (1957) examining the perceptions students held about scientists. Mead and Métraux asked approximately 35,000 high school students around the United States to write a short essay about their perspectives of science and scientists. Through the years Draw a Scientist Test (DAST) (Chambers, 1983) was patterned from Goodenough's (1926) the Draw a Man Test (now the Draw a Person Test). For facilitating ease of assessment, Finson, Beaver, and Crammond (1995) developed the Draw a Scientist Test Checklist (DAST-C). Thomas, Pedersen and Finson (2001) further modified the DAST-C to create the Draw a Science Teacher Test Checklist (DASTT-C) and used the DASTT-C to document the preservice elementary teachers' knowledge and beliefs about elementary science teaching methods. The authors also intended to provide preservice teachers with a reflective opportunity to picture themselves as future teachers and consider the ways in which they developed their own science teaching beliefs. Since interviewing each preservice teacher would be impractical, the authors added a written narrative component to the instrument which was found both to contribute some additional information and to confirm the researchers' interpretation of images in drawings. Later years, the DASTT was used for measuring the change in prospective science teachers' beliefs about science teaching after having science method and practicum courses (Ambusaidi \& Al-Balushi, 2012). 
Researchers in mathematics education, such as Picker and Berry (2000), refocussed the DAST to enable students to draw a mathematician on a blank sheet of paper and to describe the images reflected in students' drawings of mathematicians. The instrument is entitled the Draw a Mathematician Test (DAMT) which also includes a section for students to describe elements of the drawings. Through a description, Picker and Berry (2000) assumed that students would give more information about their beliefs. Later years, the use of drawing tasks, with accompanying text has been found to add rigor to the instrument as the information provided in the writing reduces the subjectivity effect in coding the drawings (Murphy, Delli, \& Edwards, 2004).

The DAMT or its modifications has been widely used to elicit data from students about their images of mathematics (e.g. Johansson \& Sumpter, 2010; Rock \& Show, 2000), mathematicians (e.g. Aguilar, Rosas, Zavaleta, \& Romo-Vázquez, 2016; Hatisaru, 2019a; Picker \& Berry, 2000), mathematics education with a focus on motivation (e.g. Johansson \& Sumpter, 2010), assessment practices in mathematics classrooms (Remesal, 2009); or as a way to evaluate teaching in mathematics classrooms (e.g. Hatisaru, 2019b; Pehkonen, Ahtee, Tikkanen, \& Laine, 2011), the kind of emotional atmosphere (Laine, Näveri, Ahtee, Hannula, \& Pehkonen, 2013) and types of work experienced in mathematics lessons (Pehkonen, Ahtee, \& Laine, 2016), and the teacher actions factor on the emotional atmosphere of mathematics classrooms (Laine, Ahtee, \& Näveri, 2020).

Drawings have also been used to assist preservice teachers to become aware of their perspectives about the nature and learning of mathematics (Mewborn \& Cross, 2007), whether their math-anxiety decrease as a result of completing their early childhood mathematics method course providing them opportunities for using and modelling manipulatives (Lake \& Kelly, 2014), and to explore how they envision their future classroom and their own and students' actions within that classroom (Utley \& Showalter, 2007). Additionally, researchers used drawings to examine preservice teachers' reflections on the way they had been taught, and the way they want to teach mathematics to their future students and found drawings to be a useful tool for enabling reflection upon past experiences and for planning future teaching (Lee \& Zeppelin, 2014).

Over the years, the use of drawings in education as a measure of students' conceptions of teaching and learning school subjects (e.g. mathematics) (Johansson \& Sumpter, 2010) have been found to be valid (Gulek, 1999; Laine et al., 2020; Losh, Wilke, \& Pop, 2008; Murphy et al., 2004), reliable (Johansson \& Sumpter, 2010; Remesal, 2009) and useful (Harris, Harnett, \& Brown, 2009), as well as a cost-effective alternative to classroom observations (Haney et al., 2004). DAST, DAMT or DASTT studies have been conducted in many countries on different continents including Europe, the Middle East, Asia, and the United States from K-12 students to pre- or in-service teachers. The drawing task in our study has been adapted from these instruments to explore school principals' views about STEM learning environments.

\section{The Study}

The study reported here was part of a national project, Principals as STEM Leaders - Building the Evidence Base for Improved STEM Learning (PASL), aimed at developing research-based professional learning (PL) for principals to effectively lead STEM in their schools. While the project drew from various models of STEM (e.g. Hobbs et al., 2018) to inform the construction of its PL resources and activities, it did not promote any particular model of STEM education to principals as best practice. Rather the PASL project sought to support principals their understanding of leading the teaching and learning of STEM disciplines taught with any degree of integration.

The study is qualitative in which data were collected using the Draw a STEM Learning Environment Test (D-STEM), adapted from Thomas et al.'s (2001) DASTT and research on using drawings to document educational phenomena (Haney et al., 2004). The first page provides a rectangular area in which participants are asked to draw. Inspired by Haney et al. (2004), the following drawing prompt is given above the rectangle: "Think about the teachers of STEM and kinds of things they do. Draw a STEM learning environment." The second page provides an open-ended item borrowed from Thomas et al. (2001) and Picker and Berry (2000), which asks participants to explain 
their drawings: "Look back at the drawing and explain your drawing so that anyone looking at it could understand what your drawing means. What does the teacher do? What do the students do? What tools do they use?" This written narrative component contributes to gaining a deeper understanding of what participants are drawn and confirming the interpretations of input in their drawings.

Participants in the research were primary $(n=10)$ and secondary $(n=11)$ school principals from across Australia attending a 2-day face-to-face workshop as part of the PASL project. At the start of the workshop, the participants were presented with the D-STEM exercise and allocated 20 minutes to complete it. Of the 23 principals who completed the exercise, 21 agreed to their D-STEM response being used as data in the research.

\section{Data Analysis}

The drawings and associated text were subjected to content analysis by utilising a deductive approach (Elo \& Kyngäs, 2008) with the coding categories determined on the basis of previous research. A D-STEM Rubric was developed, based on an extensive review of the literature related to STEM learning environments, and an analysis of initial drawing data generated earlier from a group of STEM education researchers (Hatisaru et al., 2019). The pictorial and written statement data were considered holistically, and the data were documented using excel spreadsheets.

The D-STEM Rubric includes elements of effective STEM learning environments identified by Glancy and Moore (2014), Hobbs et al. (2018) and Vasquez et al. (2013). Specifically, we looked for evidence of the indications of STEM integration, Realistic problems, the Collaborative nature of STEM, Personal experience, Multiple representations, Community-industry engagement, and the Teaching and learning of STEM (see Table 1). We coded the first six of these elements in a Likert fashion, with the extent to which each element seemed to be represented in drawings: '2- Strong indication', '1- Some indication' or '0- No indication'. The final element was coded in a dichotomous fashion, whether each sub-element seemed to be represented in drawings or not: ' 1 - There is indication' or '0No indication', due to the inability to discriminate further. Additionally, we critiqued each response thoroughly and noted which the teaching and learning practices of STEM (e.g. problem-solve, create, collect data) were present in the participants' pictures and their associated text. Participants are designated by codes (e.g. P1, P2 and so on).

The D-STEM Rubric continues to be refined based on the related literature. The latest version is provided in Table 1 representing the coding for each element and what constituted each of ' 2 ', ' 1 ' and ' 0 ' in relation to those elements. To illustrate the process, we described the coding of two responses. In Figures 1 and 2 we presented examples of two participants' drawings and their descriptions that represent elements of the D-STEM Rubric. Our judgements of the extent to which each of the elements of the Rubric are presented is shown in Table 2.

In Figure 1, there is an emphasis on learning tasks or activities that could require combining knowledge and skills from two or more disciplines (e.g. mathematics and technology) such as robotics, coding, programming with reference to designing and making, as well as science (E1: ' 1 '). Real life issues are also referenced but no further details are provided (E2: ' 1 '). It depicts a range of areas in which students work collaboratively on problems (E3: '1'). The mentioned real-life issues might be linked students' lives and elicit their interest (E4: ' 1 '). The picture captures a context that could support multiple representations and includes a symbolic representation: "+xy " (E5: '2'). No evidence of linking a content with the community (E6: ' 0 '). 
Table 1.

Elements of D-STEM Rubric and their descriptions

\begin{tabular}{|c|c|}
\hline Element & Description and level of inclusion \\
\hline & Drawing or writing includes: \\
\hline STEM integration & $\begin{array}{l}\text { 2: reference to a context that might require students to use knowledge and } \\
\text { skills from multiple STEM disciplines } \\
\text { 1: reference to a context that might require students to use knowledge and } \\
\text { skills from multiple STEM disciplines, but the nature of the problems or } \\
\text { tasks is not explicit or not real-life based } \\
0 \text { : no reference of such contexts or situations }\end{array}$ \\
\hline Realistic problems & $\begin{array}{l}\text { 2: reference to interdisciplinary problems grounded in the real world } \\
\text { 1: reference to problems that could involve realistic situations, but the nature } \\
\text { of the problems is not explicit } \\
0: \text { no reference of realistic problems }\end{array}$ \\
\hline $\begin{array}{l}\text { Collaborative nature of } \\
\text { STEM }\end{array}$ & $\begin{array}{l}\text { 2: reference to collaboration among students in which members have roles } \\
\text { and responsibilities, i.e. teamwork } \\
\text { 1: reference to collaboration/group work among students, but no explicit } \\
\text { reference to the presence of teamwork } \\
0: \text { no reference of collaboration }\end{array}$ \\
\hline Personal experience & $\begin{array}{l}\text { 2: reference to a context that problems or tasks are linked students' lives and } \\
\text { tap into/elicit their interests } \\
\text { 1: reference to a context that problems or tasks may be linked students' } \\
\text { lives and tap into/elicit their interests, but the nature of the problems is not } \\
\text { explicit } \\
0 \text { : no evidence of personal relevance }\end{array}$ \\
\hline Multiple representations & $\begin{array}{l}\text { 2: reference to a problem or context that could support multiple representa- } \\
\text { tion, and at least two representational models (e.g. symbols, visual dia- } \\
\text { grams, verbal statements) are explicit } \\
\text { 1: reference to a problem or context that could support multiple representa- } \\
\text { tion, but representational models are not explicit } \\
0: \text { no evidence of multiple representations }\end{array}$ \\
\hline $\begin{array}{l}\text { Community-industry en- } \\
\text { gagement }\end{array}$ & $\begin{array}{l}\text { 2: reference to linking content with industry, the community or families } \\
\text { in a variety of ways (expert talks, joint works, using business/community } \\
\text { contexts) } \\
\text { 1: reference to linking content with industry, the community or families, but } \\
\text { the ways of linking are not explicit } \\
0 \text { : no reference of community engagement }\end{array}$ \\
\hline Teaching and learning & Drawing or writing includes: \\
\hline $\begin{array}{l}\text { Teaching and learning } \\
\text { practices }\end{array}$ & $\begin{array}{l}\text { 1: reference to open-ended student-centred instruction (e.g. inquiry, prob- } \\
\text { lem-based) } \\
0: \text { no reference of such student-centred instruction }\end{array}$ \\
\hline Tools & $\begin{array}{l}\text { 1: reference to using a range of teaching and learning tools } \\
0: \text { no reference of tools }\end{array}$ \\
\hline Roles of the teacher & $\begin{array}{l}\text { 1: reference to the teacher roles other than giving knowledge (e.g. facilitator, } \\
\text { guide) } \\
0: \text { no reference of such teacher roles }\end{array}$ \\
\hline Roles of the students & $\begin{array}{l}\text { 1: reference to the student roles other than receiving knowledge (e.g. plan- } \\
\text { ner, experimenter) } \\
0: \text { no reference of such student roles }\end{array}$ \\
\hline
\end{tabular}




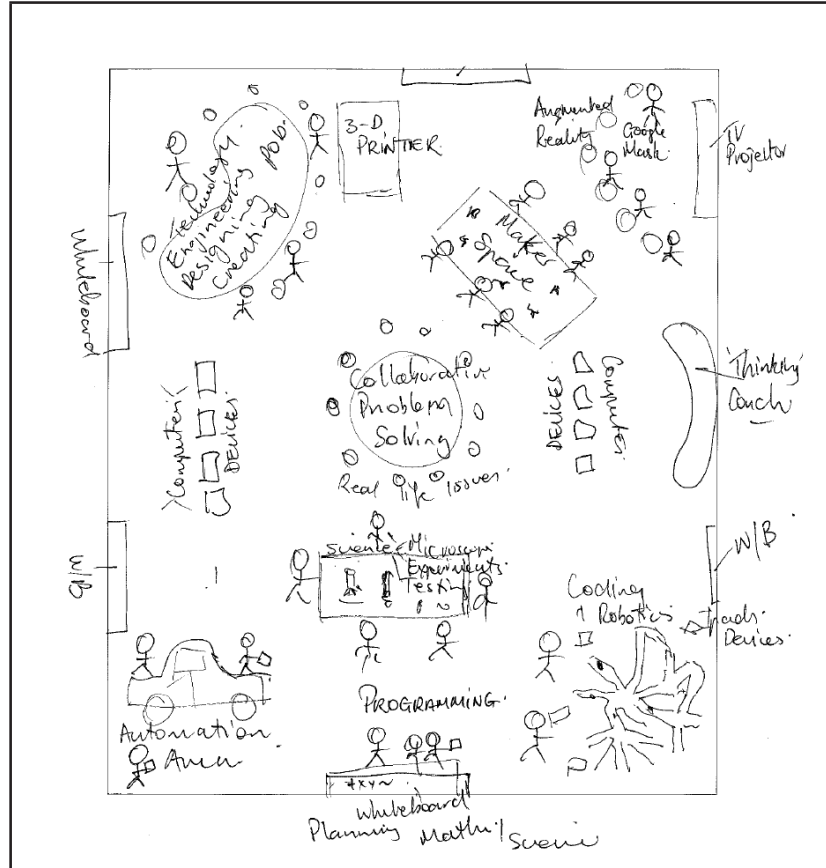

Student work: Collaborative environment for planning, designing, creating, problem solving and coming up with creative and innovative solutions. Teachers: Create provocation for students to engage \& explore. Explicitly teach foundation skills in science, maths, literacy, technology, engineering (computational thinking). Provide the condition for collaboration. Scaffold student thinking to be creative problem solver. Tools: Range of tools/ devices to do the above.

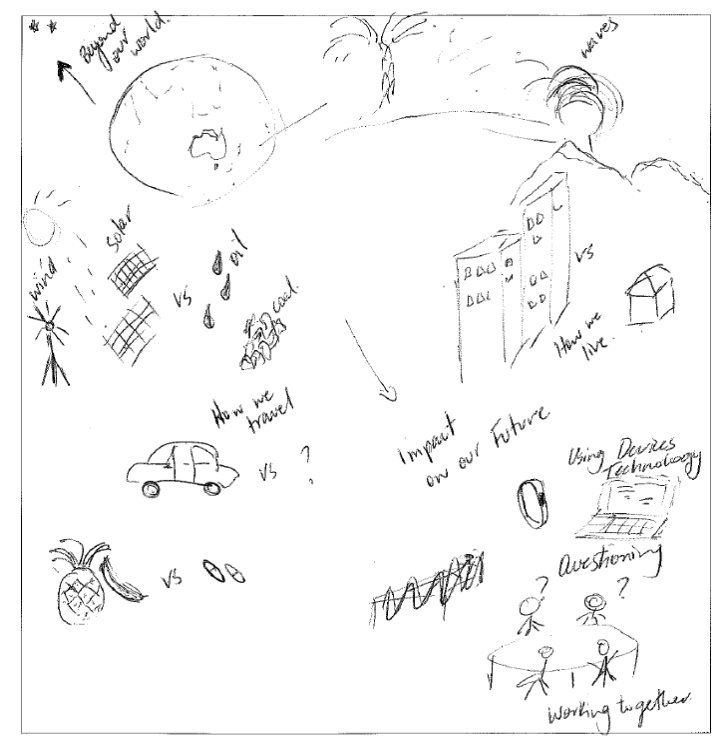

My picture is about opening up students' minds beyond our school gate looking at the impact that we are having our environment. Questioning our current practices and challenge them with new thinking. Teacher: provides a space/environment where they can question, learn new technologies/information, provide challenges/issues to explore. Students: working together in groups/ (collaboratively) (communicatively) working through issues, going and finding their own data perhaps working with experts in a special field. Tools-- whatever they need. They can be very resourceful.

Figure 1. P1's drawing and description of a STEM Figure 2. P8's drawing and description of a STEM learning environment learning environment

Both the visual and written descriptions include indicators of an open-ended student-centred instruction (E7a: '1'), and teaching and learning practices such as planning, designing, creating, problem solving, exploring, developing creative and innovative solutions, and computational thinking are mentioned. Technologies such as TV/projector, 3-D printer, computer, augmented reality, google mask are included (E7b: ' 1 '). The teacher is described in terms of their role in creating provocation for engaging students and making them to explore, as well as using the explicit teaching of foundational skills involving science, mathematics, literacy, technology and engineering (E7c: ' 1 '), while students in solving problems and coming up with creative and innovative solutions (E7d: ' 1 ').

In Figure 2, the emphasis is on a context beyond the classroom. An open-ended realistic problem (the impact that human beings have been having on the environment) which could be required combining knowledge and skills from two or more disciplines, and could be linked students' lives is provided (E1, E2 and E4: '2'). The picture captures a context that could support multiple representations but includes no specific representation (E5: ' 1 '). The emphasis in the response is, students are working collaboratively in collecting data to be able to question their current practices in relation to environmental issues (E3: ' 1 ') and possibly collaborate with experts in that field, though the nature of the collaboration with experts is not explicated (E6: ' 1 '). 
Table 2.

Assessments of D-STEM responses shown in Figures 1 and 2

\begin{tabular}{llll}
\hline Element & & Figure 1 & Figure 2 \\
\hline E1 & STEM integration & 1 & 2 \\
E2 & Realistic problems & 1 & 2 \\
E3 & Collaborative nature of STEM & 1 & 1 \\
E4 & Personal experience & 1 & 2 \\
E5 & Multiple representations & 2 & 1 \\
E6 & Community-industry engagement & 0 & 1 \\
E7 & Teaching and learning & & 1 \\
E7a & Teaching and learning practices & 1 & 1 \\
E7b & Tools & 1 & 1 \\
E7c & Roles of the teacher & 1 & 1 \\
E7d & Roles of the students & 1 & \\
\hline
\end{tabular}

In like Figure 1, indicators of an open-ended student-centred instruction are evident (E7a: ' 1 '). Perceived teaching and learning practices involve generating questions, learning new technologies, gaining information, collecting data and exploring. Students use technology, and at the same time, according to the creator, they can be very resourceful (E7b: ' 1 '). The teacher's role is described as providing the environment, and the challenges or issues that students explore. Also references to expanding students' thinking, encouraging a critical orientation to current practice and self-reliance in terms of sourcing data (E7c: ' 1 '). Students critique and are e.g. collaborator and experimenter (E7d: '1').

To ensure reliability of the results, the first and the second authors independently coded ten D-STEM responses achieving 87\% agreement. Disagreements were resolved through discussion to reach consensus, which involved the examination of item descriptions which were unclear and/ or needed modification. Throughout the coding process, they consistently discussed issues that required attention or needed resolution. The data from the drawings and writing were tallied and summarised. Both the participants' pictures and their own words were used in data analysis and reporting.

\section{Results}

Table 3 shows the frequency of visual and/or written descriptions scoring ' 2 ', ' 1 ' or ' 0 ' for each of first six elements of the STEM learning environments. In this section, we present findings of the participants' views with reference to these elements, giving examples from their pictures or text. Details about the final element, the Teaching and learning of STEM, are provided later in the section.

\section{STEM integration}

In general, it was difficult to interpret the extent to which the STEM subjects are integrated in participants' responses. While they did not indicate that the four STEM subjects are taught in an isolated manner, interpretation of the extent of integration was hampered by the nature of the problem or task in which students are engaged being unspecified or unclear. For example, in eight responses (P3, P9, P12, P15, P16, P18, P21 and P23) there was no reference to a problem or context (e.g. see Figure 3), and in a further three responses (P2, P6 and P10) the learning environment is described as students working on real life issues, STEM investigations or projects, but the nature of problem was not explicitly stated (e.g. see Figure 4). 
Table 3.

The frequency of D-STEM responses at each level for each element $(N=21)$

\begin{tabular}{lccc}
\hline Element & $\begin{array}{c}\text { Drawing/writing } \\
\text { includes strong } \\
\text { reference ' } \mathbf{2}^{\prime}\end{array}$ & $\begin{array}{c}\text { Drawing/writing in- } \\
\text { cludes reference '1' }\end{array}$ & $\begin{array}{c}\text { Drawing/writing in- } \\
\text { cludes no reference '0' }\end{array}$ \\
\hline STEM integration & 3 & 11 & 8 \\
Realistic problems & 2 & 6 & 13 \\
Collaborative nature of STEM & 3 & 18 & 0 \\
Personal experience & 4 & 5 & 12 \\
Multiple representations & 3 & 9 & 9 \\
Community-industry engagement & 0 & 1 & 20 \\
\hline
\end{tabular}

Based on the depicted and described contexts in the remaining eleven responses, there was evidence of a moderate or extensive degree of integration. In eight of them (P1, P4, P5, P7, P11, P13, P14 and P20) reference was made to learning tasks or activities that could require combining knowledge and skills from two or more areas such as Robotics $(f=5)$, Coding $(f=4)$, Programming $(f=2)$, Cooking $(f=2)$, Gardening $(f=2)$, 3D Printing $(f=1)$, Recycling $(f=1)$, Construction $(f=1)$, Manufacturing $(f=1)$, Virtual Design $(f=1)$ or Environmental Sciences $(f=1)$. A STEM unit designed to incorporate these practices would combine knowledge and skills from two or more disciplines (e.g. science and mathematics or engineering) that are important for all students to learn. Planning the unit around common learning objectives across these disciplines would emphasise interdisciplinary knowledge or skills for students.

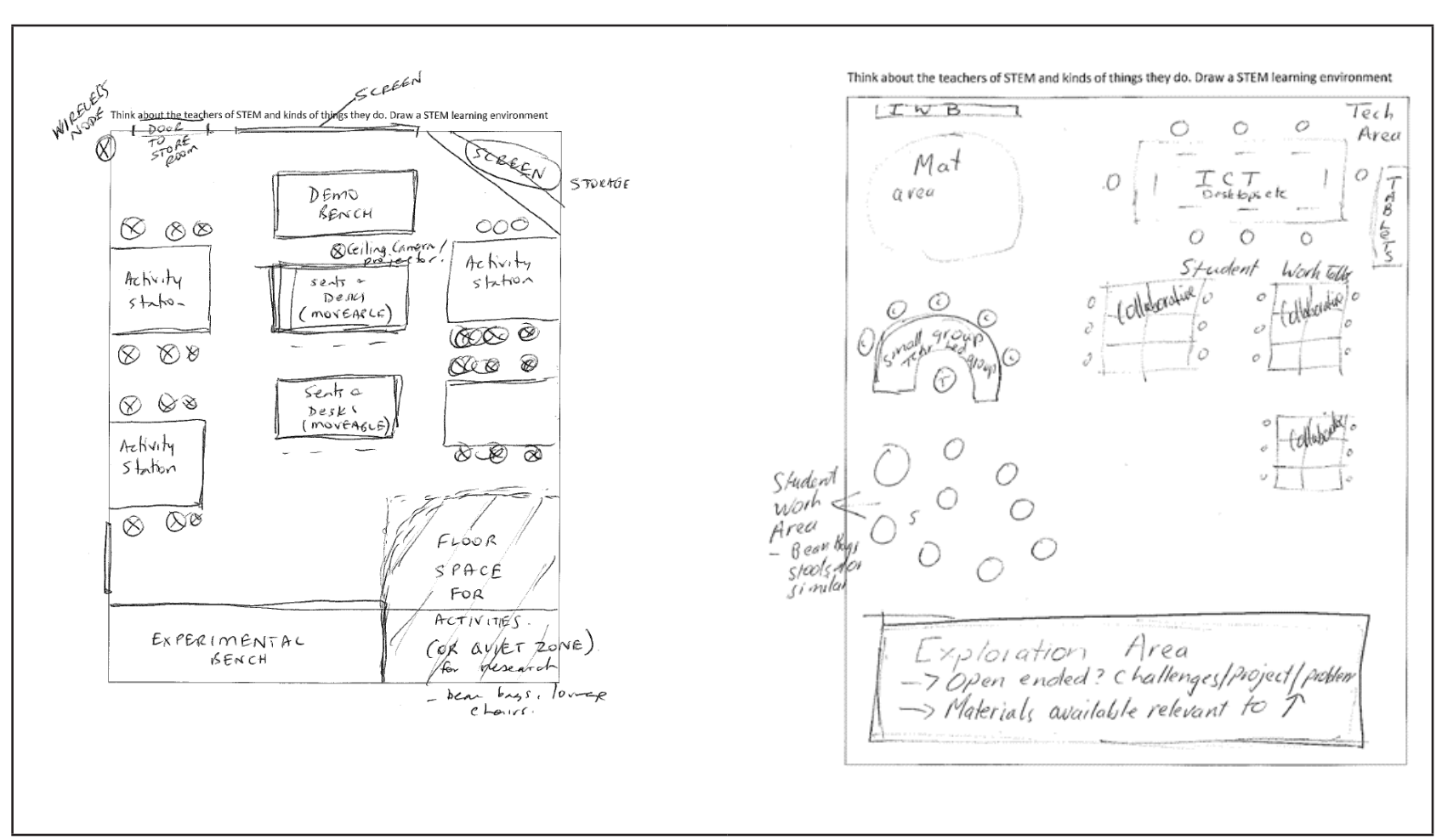


The idea is to create a semi-flexible, semi-permanent workspace where collaboration, experimentation and individual work can occur as needed. The design allows teachers to instruct as necessary allow supervision but provide opportunities for students to work at their own rate. Students use notebooks/ iPads and access online resources. They can use various equipment resources available to complete experiments. They have data loggers, robotics equipment etc. There is ceiling mounted camera to record the activities teleconference.
The area is designed to enable a combination of Teacher Led explicit instruction in two areas. Whole Group-Mat Area a small group at the U shaped table. Students have 3 Areas to work in. Collaborative Tables of 6 students ICT AREA- includes laptops/ tablets that can be used in other areas. Area where students can work at (non tables). A large area at back of the room is for exploration of problem/challenge/ investigation the class/students are undertaking. Materials, equipment in this area is there to support a compliment the STEM investigations may chance with the topic/area being investigated.

Figure 3. P9's drawing and description of a STEM Figure 4. P6's drawing and description of a STEM learning environment

learning environment

In the other three responses (P5, P8 and P19) the potential for extensive integration was apparent, as is evident in one of those responses described below:

The teacher demonstrates how to do a 3D print of the Eiffel Tower. One student uses a drone to film this and project on a screen. Students are working independently/remotely on different aspects of STEM research, communication, investigation. A girl has programmed a new robot. In another scenario they are all working separately on aspects of one topic/ project (e.g. sustainability) to add the body of knowledge \& learning. (P5)

In another, "STEM learning occurs outside of the classroom and within. It has a focus on the world outside of the school to create meaning within the school.", and an environment in which students are observing and measuring environmental conditions in field side with the use of STEM knowledge and resources at the school is pictured (P19). Although no more detail is given, we believe in the context of such a field work environment (P19) or in working on a project about "sustainability" (P5), students could apply their knowledge and skills from multiple disciplines to real world applications. In the image provided by P8 (see Figure 2), the goal was embedded in a real-world context: "... the impact that we are having our environment". In these responses, the focal points were the relevance of the students' learning and students' ability to use their knowledge in a real-world context. We understood that these contexts of the potential of an extensive level of integration, because students would apply their knowledge and skills in real-world situations.

\section{Personal experience}

As the responses of P5, P8 and P19 involved situations from real life, we assumed that students could relate and engage with the problems and make sense of them based on their own experiences and might encounter with the problems in their lives outside of school. In addition, P13 emphasised this personal experience aspect stating that:

In my drawing there are a variety of STEM projects happening including robotics, computer coding/research. Maths learning which involved hands-on games [materials] and resources often applied to real-life, authentic purpose. Literacy is fundamental to STEM learning and quality literature, informational texts inform this. The environment features significantly including the outdoors. Construction cooking, other project-based activities, real life contexts ensure STEM learning is applied to the child's world.

In six responses (P1, P2, P10, P14 and P20) it was evident that the learning might be applicable or useful for students outside of the school. While real-world issues or problems were referred to, but the nature of the problem was not given in three responses (P1, P2 and P10), the other two responses (P14 and P20) included references to how new learning would be applicable and useful for students. P14's response indicated the importance of appealing to the curiosity of students through learning how or what make things work: "There is a makerspace with real tools as well as other materials 
to build prototypes. There is a breakerspace where students can pull apart old computers, bikes etc to learn how things work and then repurpose these parts". While P20's response highlighted the usefulness of "a kitchen/garden program" in which learning objectives could be embedded into: "A kitchen/garden program can also be part of a STEM space in which STEM activities are linked to the curriculum through cooking and growing" (P20). In the remaining responses no reference was made to the personal experience.

\section{Collaborative nature of STEM}

All responses included clear indications of students collaborating or working in groups. Almost all participants drew or described a context in which students are interacting and working together to find solutions to problems or running investigations or projects (e.g. Figure 1 and 2). A few responses (P2, P5 and P7), however, included more specific indications of the collaborative nature of STEM, that is, students working in teams, with each member taking on specific roles and responsibilities. P5's response was indicative: "[students] are all working separately on aspects of one topic/project (e.g. sustainability) to add the body of knowledge \& learning". Although not explicitly stated, we inferred that P2 and P7 also referred to the collaborative nature of STEM. As can be seen in Figure 5, P2 stated: "[Students] Prepare design brief. Work in teams to provide ways of solving problems.". Similarly, as P7, wrote:

STEM learning is about an inquiry-based approach to solving problems. There is a known methodology to apply but the STEM team work collaboratively to generate creative solutions to challenges. ... A STEM environment does not predetermine an outcome and allows individualism, collaboration to work together.

\section{Multiple representations}

In effective STEM learning environments learning activities are structured both to use different modes of representations (e.g. diagrams, concrete models, written symbols) and to translate between these representational modes. Identifying translation between modes from only drawings and text was difficult, so our analysis did not include a study of the extent to which there was a potential for translation. Rather we determined if a context was described in which students use representations and if some representations were pictured.

The analysis showed that the responses of nine participants (P3, P4, P5, P7, P8, P11, P14, P19 and P20) included reference to tasks or activities (e.g. programming, robotics type of work, an investigation about sustainability, virtual design, and a kitchen/garden program) through which concepts or ideas relevant to individual STEM subjects could be presented through different representational modes (e.g. spoken language, written symbols, diagrams, concreate models, metaphors). Usually, however, the representational modes were not made explicit. Only three participants (P1, P2 and P13) both depicted or described a context which is open to use multiple representations of a concept and gave clear indicators to one of the five distinct representation systems. It can be seen in both Figure 1 (P1) and Figure 5 (P2), that in addition to including a context open to using different representations, the participants included symbolic representations respectively: " $+x y^{\sim}$ " and " $x+y=3-3 / 41^{3 \prime}$. The third participant (P13) stated: "Maths learning which involved hands-on games [materials] and resources often applied to real-life, authentic purpose", and included "(dice, number charts, peg lines)" in the drawing and labelled them as "hands-on materials [manipulative models]".

\section{Community-industry engagement}

Community-industry engagement in the STEM learning environment was rarely evident in the drawings. P8's response, (see Figure 2), was the only one in which reference was made to community-ind ustry engagement in the STEM learning environment. In this drawing, the participant represented students outside the classroom working on wicked problems relevant to the world in which they live (and beyond into outer space). The participant's supporting text highlighted her perspective when she considered a STEM learning environment: "[Students are] working together in groups/(collaboratively) (communicatively) working through issues, going and finding their own data perhaps working with experts in a special field" (P8). From this statement it was not clear how 
"experts in a special field" would be linked with learning objectives, but the participant might see the engagement of students with experts in a complex inquiry task to support and maximise the learning of STEM in students.

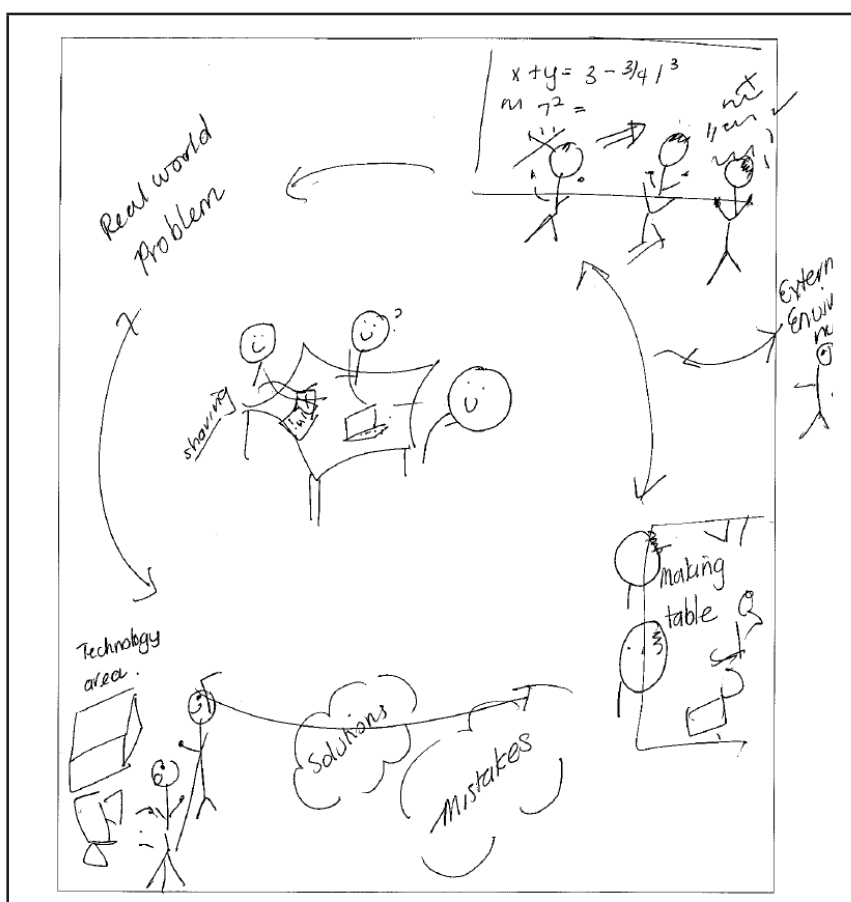

A real word problem. Teachers: Set the challenge/ design brief/problem. Guide the process. Students: Prepare design brief. Work in teams to provide ways of solving problems. Tools: Digital technologiescomputers, - coding/robotics). Making tools- can be anything. Flexible learning environment.

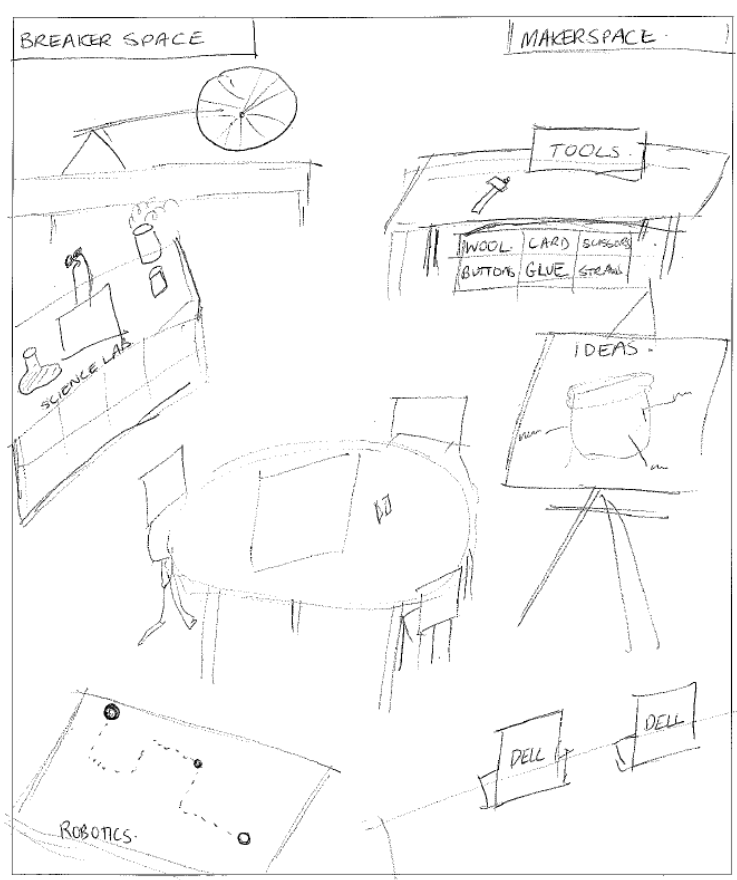

Teachers use a range of materials to explore, invent and create. They have a space for collaboration and brainstorm their ideas. There are computers to research and also code, including with robotics devices. There is a makerspace with real tools as well as other materials to build prototypes. There is a breaker space where students can pull apart old computers, bikes etc to learn how things work and then repurpose these parts. There is a science lab for experimentation. These various sections can be used separately and/or in an integrated manner, depending on the project.

Figure 5. P2's drawing and description of a STEM Figure 6. P14's drawing and description of a STEM learning environment learning environment

The teaching and learning of STEM

Table 4 provides the frequency of visual and/or written descriptions corresponding to the final element, the Teaching and learning of STEM. It was included separately as the drawings were analysed on a two-point scale (present/absent), rather than the three-point scale used in the other elements. 
Table 4.

The frequency of D-STEM responses at each level for each element $(N=21)$

\begin{tabular}{lcc}
\hline Element & $\begin{array}{c}\text { Drawing/writing includes } \\
\text { reference '1' }\end{array}$ & $\begin{array}{c}\text { Drawing/writing includes no } \\
\text { reference '0' }\end{array}$ \\
\hline The teaching and learning of STEM & 18 & 3 \\
Teaching and learning practices & 20 & 1 \\
Tools & 16 & 5 \\
Roles of the teacher & 18 & 3 \\
Roles of the students & & \\
\hline
\end{tabular}

The analysis showed that most responses $(n=18)$ represented contexts in which experiential and open-ended approaches such as science inquiry, engineering design or problem-based learning (PBL) are implemented, and students investigate solutions to tasks or problems through designing, testing and revising their ideas. The drawing and text from P1 (see Figure 1) and the texts from P3 and P23 provided indicative responses:

21st C skills- resilience, asks questions, curious, being self-aware, collaborative. Inductive learning: Instead if here is the knowledge, now go practice it --- here are some objects, experience, data- what knowledge can we gain from it? (PBL/Inquiry learning). (P3)

Problem identified-shared-ideas generated as group $\longrightarrow$ Work can go to research or 'THINK TANK' to further develop or plan their solutions $\longrightarrow$ Materials can be gathered to then $\longrightarrow$ Test their solutions $\longrightarrow$ Shared experience/group feedback/even better if. (P23)

These eighteen responses included explicit references to teaching and learning practices. The practices commonly identified were: making things $(f=11)$, testing or experimenting $(f=11)$, working with or using/learning different technologies or equipment $(f=10)$, inquiring $(f=9)$, solving problems $(f=5)$ and developing/creating solutions $(f=5)$, designing processes/products $(f=3)$, asking/generating questions $(f=3)$ and planning $(f=3)$. Collecting information $(f=4)$ or data $(f=1)$ and interpreting $(f=1)$ data, and computational thinking $(f=1)$ were also evident.

Almost all responses $(n=20)$ showed that an essential part of STEM learning environment is the integration of technology, digital tools and various equipment pertinent to the STEM practices depicted and discussed. For instance, in P18's response:

Students collaborate together to work on questions/problems- utilising a range of tools+equip. The classroom/workshop provides: Space for collaboration/discussions/ design, Space for building + assembling +experimenting, Space for whole class teaching and individual spaces for quite thinking. Computers/Technology access: Access to science habs + design spaces. Students use a range of equipment: including technology, scientific, building equipment tools Robotics/lego/3D printers laser cuttlers/Virtual reality programmes/mine craft/drones Design programs--- CAD, etc; coding.

P1 depicted electronic materials (TV/projector, Computer, 3D printer), science equipment, and digital tools (Augmented reality, Google mask) as being available to students for use in "collaboration problem solving" (see Figure 1). P14 described a context in which "a range of materials to explore, invent and create" including "computers to research and also code, including with robotics devices", a makerspace "with real tools as well as other materials to build prototypes" and "a science lab for experimentation" to be used "separately and/or in an integrated manners, depending on the project" (see Figure 6). What was less apparent in the responses was the presence of representational forms of ideas/concepts related to STEM subjects allowing these ideas/concepts to be communicated in e.g. graphs, tables or diagrams. 
In most responses the active role of the teacher $(n=16)$ and students $(n=18)$ in STEM teaching and learning environments was evident. The teacher and students were described or pictured as interacting in an environment in which the teacher is no longer just the knowledge giver, and students are no longer only knowledge receivers. Rather the teacher guides or facilitates the learning, and students are active, and take on roles other than listener or knowledge receiver including collaborator, maker and experimenter. As can be seen in Figure 2, the learning environment that P8 represented includes students working in groups to solve problems and appears to portray pedagogies that include students engaging thoroughly in the learning process and authentic inquiry. Similarly, P2 (see Figure 5) represented an environment in which creativity and student autonomy are encouraged and in which students link the knowledge they learn at school with the "External Environment". anymore:

Among the whole group, three participants indicated that the teacher is not an 'expert'

The teacher is the facilitator to help students direct their learning journey--- helping guide the personal discovery linked to the outcomes to enhance their learning within the curriculum framework or beyond. Students can use a range of spaces and learning styles to gain the depth of understanding required. Students use the latest technology and teach the teacher this part as shared learners. The teacher is not expected to be the expert any more. Creative Critical Thinking Citizens. (P15)

A hive of activity where students can engage in deep learning in an open learning environment. The space has flexibility and encourages collaboration, creativity, communication, critical thinking etc. The teacher collaborates with the students and is as much a learner as the students. They are not expert in the room. (P16)

The teacher collaborates and acts as facilitator and guide mostly. Often the teacher is also the co-learner. ICT is a major tool used including traditional as well as new and innovative technologies. A kitchen/garden program can also be part of a STEM space in which STEM activities are linked to the curriculum through cooking and growing. (P20)

From these few responses it was not clear what the notion that the teacher is no longer 'expert' refers. It could refer to the fact that the problems are so diverse and draw from several STEM disciplines, that teachers can no longer have the level of expertise that the complexity of the problems requires, or it could be that STEM learning environments free the teacher from the need to be perceived as the expert.

\section{Discussion, Implications, and Future Directions}

The results reported here relate to perceptions of school principals with respect to STEM learning environments as revealed in their drawings and associated verbal statements. The study sought to answer the research question: What are school principals' perceptions of effective STEM learning environments? A further contribution of the study is methodological in response to the question: How can established drawing-based techniques be adapted as a way of uncovering principals' perceptions of STEM learning environments?

The drawing task elicited a wide variety of responses which varied in range and reflected a diversity of interpretations of STEM learning environments. The two elements most commonly depicted in participants' responses were: working collaboratively in groups, and using open-ended student-centred teaching and learning practices; while a focus on the opportunities that STEM learning environments provide to link content with industry and the community was almost absent. We were surprised that most of the responses reflected participants' perspectives about studentcentred instruction. Very few responses depicted and/or described teaching and learning practices anchored in realistic problems, which can enable the integration of individual STEM disciplines, and engage students in the translation of concepts across multiple representations. This is interesting 
because it suggests that for most participant principals, the phrase 'STEM learning environment' equated to the use of student-centred pedagogies in classrooms, where students work collaboratively, and the teacher's main role is to motivate and facilitate their learning.

Adopting student-centred pedagogies does not reduce the teacher's responsibility for designing and overseeing student learning or their need to develop and apply specific expertise in the STEM learning environment (Keiler, 2018). Consequently, the three participant principals' statements that describe the teacher as a 'co-learner', or that the teacher is no longer expected to be the 'expert', warrant further investigation. The extent to which an individual teacher needs to be knowledgeable about all science, technology, engineering and mathematics practices in STEM learning environments, described by Vasquez et al. (2013) is as yet unexplored (see exceptions e.g. Chan, Yeh, \& Hsu, 2019; Srikoom, Faikhamta, \& Hanuscin, 2018), but the fact that expertise is required is clear (Allen, Webb, \& Matthews, 2016).

Principals' drawings and text indicated that they placed more emphasis on science, engineering and technology practices (e.g. making/designing, testing or experimenting, and working with or using/learning different technologies) than mathematical practices in the drawings and descriptions. While of concern, this outcome is useful for mathematics educators, as the D-STEM instrument reveals its potential to draw attention to the presence or otherwise of mathematics in an integrated environment and to confirm or assuage fears that mathematics may be neglected in such contexts (Fitzallen, 2015). In addition, it has the potential to highlight the ways in which mathematics is portrayed in these environments. The latter offers an opportunity to re-emphasise the value of research-based approaches to mathematics teaching (e.g. Sullivan, 2011) and STEM education more broadly.

As discussed, the literature emphasises the importance of incorporating opportunities for students to work with different modes of representations as they learn STEM concepts. Data analysis of principals' drawings and text revealed that only a small number of participants incorporated different modes of representations in their learning environments or referenced tasks or activities that could draw from different representational modes. In most of their diagrams and text, the use of representational tools remains implicit or is absent altogether. In order to determine the real extent to which multiple representations are incorporated into STEM learning environments and the problems/projects that students engage in, this element would need to be the focus of observation in classroom settings.

Principals treated the drawing-based technique, designed to elicit their perceptions of STEM learning environments as a serious task, taking some considerable amount of time to capture their responses. In addition, it is our observation that drawings contain rich information relating to understanding of STEM learning environments in educators active in STEM education (Hatisaru et al., 2019). We take these as evidence of the success of the drawing method as a means of investigating individual views about STEM learning environments. As anticipated, it was methodologically very useful to include the prompt requesting participants to look back at the drawing and explain it so that anyone looking at it could understand it. This addition enabled us to clarify the information contained in the drawings and to enhance our interpretation of the STEM learning environments depicted.

The D-STEM Rubric continues to be refined based on the related literature and the ongoing collection of additional data. The D-STEM Rubric reported on here is the second version and points to the need to hone it further, through trialling both it and the D-STEM instrument with larger groups of participants including teachers of STEM disciplines and their students. However, our research confirms that drawings have the potential to "provide a valuable catalyst to document, change, and improve what goes on in schools" (Haney et al., 2004, p. 243). Importantly, this research has revealed the usefulness of the D-STEM instrument and its rubric as a methodology for unearthing the ways in which principals think about STEM learning environments. Making their thinking visible in this way, enables a discussion of the presence and absence of elements in learning environments revealed as being essential for effective STEM learning. Participating in such an activity both challenges conceptions and stimulates thinking about how such learning environments could be constructed 
as well as the dispositions and skills that they, and both teachers and students need to possess or develop in order to engage in rich STEM learning. The data reported here points to the need for professional development in STEM education designed specifically for principals, aimed at building their capacity to both understand the need for effective instructional leadership in relation to the pedagogical and curricular elements of STEM teaching that the D-STEM Rubric involves and to enact it in their schools.

While the D-STEM instrument and its associated rubric have enabled an understanding of principals' conceptions of STEM learning environments, data analysis revealed that the instrument itself could be further improved. In our development of the D-STEM instrument for use with principals, we acknowledged that not all principals teach or if they do, STEM subjects may not be their area of expertise. Hence, in order to explore their thinking about STEM learning environments, we provided them with the prompt: "Think about the teachers of STEM and kinds of things they do. Draw a STEM learning environment." We acknowledge that the prompt itself may have influenced the type of drawings and responses we obtained. For example, direct reference to the teacher in the prompt may influence their being in the image, and the absence of any reference to learning objectives may diminish the importance of student learning in their thinking.

While acknowledging that the D-STEM instrument and its rubric will benefit from further evaluation and enhancement, this research suggests several other lines of inquiry for the future. As discussed earlier, drawing methodology is a powerful approach to unearthing perceptions about phenomena but it is limited. When something is absent from a drawing and text, does that mean that it is absent from perceptions or just the response? A case in point is the near absence of reference to representational tools (e.g. diagrams, graphs, written symbols) in principals' drawings. Understandings about both of this element (multiple representations) and others (e.g. realistic problems) (see Table 1) recognised as being important for STEM learning, would benefit from classroom observation guided by the D-STEM Rubric elements in Table 1. Similarly, the extent to which these elements are present in learning environments could be assessed with respect to student performance and learning outcomes and/or teacher professional knowledge and dispositions. Indeed, using the D-STEM methodology to interrogate the outcomes of professional learning on the latter aspects of teacher practice could prove useful in measuring change.

\section{Conclusion}

The version of the D-STEM Rubric presented here emerged from analysis of the responses of school principals and initiates a new area of research concerning the ways in which these school leaders perceive STEM learning environments. It enables consistent messaging about, as discussed Bybee (2013), what STEM looks like in the classroom, and whether anything and everything in relation to the individual STEM subjects are STEM.

The D-STEM instrument and its rubric were developed based on an extensive literature review and initial empirical data from researchers active in STEM education (Hatisaru et al., 2019). Given that STEM education, undertaken either as separate disciplines or integrated to a greater or lesser extent, is positioned as a key strategy for fostering economic development and prosperity. The D-STEM Rubric represents an initial contribution to providing STEM educators and researchers with a tool for considering the breadth and quality of STEM learning environments.

\section{Acknowledgement}

Principals as STEM Leaders - Building the Evidence Base for Improved STEM Learning (PASL) is an initiative of, and funded by, the Australian Government Department of Education, Skills and Employment. 


\section{References}

Aas, M., \& Paulsen, J. M. (2019). National strategy for supporting school principal's instructional leadership. Journal of Educational Administration, 57(5), 540-553.

Aguilar, M. S., Rosas, A., Zavaleta, J., \& Romo-Vázquez, A. (2016). Exploring high-achieving students' images of mathematicians. International Journal of Science and Mathematics Education, 14(3), 527-548.

Allen, M., Webb, A. W., \& Matthews, C. E. (2016). Adaptive teaching in STEM: Characteristics for effectiveness. Theory into Practice, 55(3), $217-224$.

Ambusaidi, A. K., \& Al-Balushi, S. M. (2012). A longitudinal study to identify prospective science teachers' beliefs about science teaching using the draw-a-science-teacher-test checklist. International Journal of Environmental \& Science Education, 7(2), 291-311.

Atkinson, R. D., \& Mayo. M. (2010). Refuelling the U.S. innovation economy: Fresh approaches to science, technology, engineering and mathematics (STEM) education. Washington DC: The Information Technology and Innovation Foundation.

Australian Academy of Sciences. (2016). The mathematical sciences in Australia: A vision for 2025. Canberra: Australian Academy of Science.

Australian Curriculum, Assessment and Reporting Authority. Australian Curriculum: Mathematics. Available at https://www.australiancurriculum.edu.au/f-10-curriculum/mathematics/

Barrington, F., \& Evans, M. (2014). Participation in Year 12 mathematics 2004-2013. AMSI. Retrieved from https:// amsi.org.au/publications/participation-year-12-mathematics-2004-2013/

Beswick, K. (2007). Teachers' beliefs that matter in secondary mathematics classrooms. Educational Studies in Mathematics, 65(1), 95-120.

Bybee, R. W. (2010). Advancing STEM education: A 2020 vision. Technology and Engineering Teacher, 30-35.

Carpenter, D. M., \& Peak, C. (2013). Leading Charters: How Charter School Administrators Define Their Roles and Their Ability to Lead (0892-0206). Retrieved from https://search.ebscohost.com/login.aspx?direct=true\&d $\mathrm{b}=$ eric\&AN=EJ1019635\&site=ehost-live http://dx.doi.org/10.1177/0892020613487919

Chambers, D. W. (1983). Stereotypic images of the scientist: The Draw-a-Scientist Test. Science Education, 67(2), 255-265.

Chan, K., Yeh, Y.-F., \& Hsu, Y.-S. (2019). A framework for examining teachers' practical knowledge for STEM teaching. In Y.-S. Hsu (Ed.), Asia-Pacific STEM teaching practices: From theoretical frameworks to practices (pp. 39-50). Singapore: Springer.

Common Core State Standards for Mathematics. Available at http://www.corestandards.org/wp-content/ uploads/Math_Standards.pdf

Crawford, B. (2000). Embracing the essence of inquiry: New roles for science teachers. Journal of Research in Science Teaching, 37(9), 916-937.

Driver, R., Newton, P., \& Osborne, J. (2000). Establishing the norms of scientific argumentation in classrooms. Science Education, 84, 287-312.

Elo, S., \& Kyngäs (2008). The qualitative content analysis process. Journal of Advanced Nursing, 62(1), 107-115. doi: 10.1111/j.1365-2648.2007.04569.x

Evans, I. M., Harvey, S. T., Bucley, L., \& Yan, E. (2009). Differentiating classroom climate concepts: Academic, management, and emotional environments. New Zealand Journal of Social Sciences, 4(2), 131-146. doi: doi. org/10.1080/1177083X.2009.9522449.

Finson, K. D., Beaver, J. B., \& Cramond, B. L. (1995). Development and field test of a checklist for the Draw-aScientist Test. School Science and Mathematics, 95(4), 195-205.

Fitzallen, N. (2015). STEM education: What does mathematics have to offer? In M. Marshman (Ed), Mathematics Education in the Margins. Proceedings of the 38th annual conference of the Mathematics Education Research Group of Australasia, Sunshine Coast, (pp. 237-244). Sydney: MERGA.

Fraser, B. (2014). Classroom learning environments: Historical and contemporary perspectives. In Lederman, N. and Abell, S. (Eds). Handbook of Research on Science Education Volume II (pp. 104-119). USA: Routledge.

Gerard, L. F., Bowyer, J. B., \& Linn, M. C. (2008). Principal leadership for technology-enhanced learning in science. Journal of Science Education and Technology, 17(1), 1-18.

Glancy, A. W., \& Moore, T. J., (2013). Theoretical foundations for effective STEM learning environments. School of Engineering Education Working Papers. Paper 1.

Goodenough, F. L. (1926). Measurements of intelligence by drawings. World Book Co.

Goos, M., Geiger, V., \& Dole, S. (2014). Transforming professional practice in numeracy teaching. In Y. Li, E. Silver \& S. Li (Eds.), Transforming mathematics instruction: Multiple approaches and practices (pp. 81-102). New York: Springer.

Gulek, C. (1999). Using multiple means of inquiry to gain insight into classrooms: A multi-trait multi-method approach 
(Unpublished doctoral dissertation). Boston College, Chestnut Hill, MA.

Haney, W., Russel, M., \& Bebell, D. (2004). Drawing on education: Using drawings to document schooling and support change. Harvard Educational Review, 74(3), 241-271.

Harris, L. R., Harnett, J. A., \& Brown, G. (2009). “Drawing” out student conceptions: Using pupils' pictures to examine their conceptions of assessment. In D. M. McInerney, G. T. L. Brown, \& G. A. D. Liem (Eds.), Students perspectives on assessment: What students can tell us about assessment for learning (pp. 53-83). Charlotte, NC: Information age publishing, Inc.

Hatisaru, V., Beswick, K., \& Fraser, S. (2019). STEM learning environments: Perceptions of STEM education researchers. In G. Hine, S. Blackley, \& A. Cooke (Eds.), Proceedings of the 42nd annual conference of the Mathematics Education Research Group of Australasia (pp. 340-347). Perth: MERGA.

Hatisaru, V. (2019a). Lower secondary students' views about mathematicians depicted as mathematics teachers. LUMAT: International Journal on Math, Science and Technology Education, 7(2), 27-49. https://doi. org/10.31129/LUMAT.7.2.355

Hatisaru, V. (2019b). Putting the spotlight on mathematics classrooms. In J. Novotná \& H. Moraová (Eds.), Proceedings of the International Symposium Elementary Mathematics Teaching (pp. 182-192). ISBN 9788076030695.

Hobbs, L., Clark, J. C., \& Plant, B. (2018). Successful students - STEM program: Teacher learning through a multifaceted vision for STEM education. In R. Jorgensen \& K. Larkin (Eds.), STEM education in the junior secondary (pp. 133-168). Singapore: Springer Nature.

Johansson, D. A., \& Sumpter, L. (2010). Childrens' conceptions about mathematics and mathematics education. In K. Kislenko (Ed.), Proceedings of the MAVI-16 conference June 26-29, 2010 (pp. 77-88). Tallinn, Estonia: Tallinn University of Applied Sciences.

Keiler, L. S. (2018). Teachers' roles and identities in student-centred classrooms. International Journal of STEM Education, 34(5), 1-20.

Kennedy, T. L., \& Odell, M. R. L. (2014). Engaging students in STEM education. Science Education International, 24(3), 246-258.

Lake, V. E., \& Kelly, L. (2014). Female preservice teachers and mathematics: Anxiety, Beliefs, and Stereotypes. Journal of Early Childhood Teacher Education, 35(3), 262-275.

Laine, A., Näveri, L., Ahtee, M., Hannula, M. S., \& Pehkonen, E. (2013). Emotional atmosphere in third graders' mathematics classroom - An analysis of pupils' drawings. Nordic Studies in Mathematics Education, 17(34), 101-116.

Laine, A., Ahtee, M., \& Näveri, L. (2020). Impact of teachers' actions on emotional atmosphere in mathematics lessons in primary school. International Journal of Science and Mathematics Education, 18, 163-181. doi: doi. org/10.1007/s10763-018-09948-x

Lee, J-E, \& Zeppelin, M. (2014). Using drawings to bridge the transition from student to future teacher of mathematics. International Electronic Journal of Elementary Education, 6(2), 333-346.

Lewthwaite, B. (2004). 'Are you saying I'm to blame?' Exploring the influence of a principal on elementary science delivery. Research in Science Education, 34(2), 137-152.

Losh, S. C., Wilke, R., \& Pop, M. (2008). Some methodological issues with "Draw a Scientist Tests" among young children. International Journal of Science Education, 30(6), 773-792.

Likourezos, V., Beswick, K., Geiger, V., \& Fraser, S. (2020). How principals can make a difference in STEM education. Australian Educational Leader, 42(2), 33-36.

National Council of Teachers of Mathematics (1989). Curriculum and evaluation standards for school mathematics. Reston VA: Author.

National Council of Teachers of Mathematics (2000). Principles and standards for school mathematics. Reston VA: Author.

National Council of Teachers of Mathematics (2014). Principles to actions: Ensuring mathematical success for all. Reston VA: Author.

Nelson, B. S. (2010). How elementary school principals with different leadership content knowledge profiles support teachers' mathematics instruction. New England Mathematics Journal, 42, 43-53.

Matthews, S. (2012). A note on 'image' methodology for social work qualitative research: Socially inclusive research methods for service users. Social Work \& Social Sciences Review, 15(3), 119-127.

Mead, M., \& Metraux, R. (1957). Image of the scientist among high school students: A pilot study. Science, 126, 384-390.

Mewborn, D. S., \& Cross, D. I. (2007). Mathematics teachers' beliefs about mathematics and links to students' learning. In W. G. Martin, M. E. Strutchens, \& P. C. Elliot (Eds.), The learning of mathematics (pp. 259-269). Reston, VA: NCTM. 
Murphy, P. K., Delli, L. A. M., \& Edwards, M. N. (2004). The good teacher and good teaching. Comparing the beliefs of second-grade students, preservice teachers, and inservice teachers. The Journal of Experimental Education, 72(2), 69-92.

Office of the Chief Scientist. (2012). Mathematics, engineering and science in the national interest. Canberra: Commonwealth of Australia

Pape, S. J., \& Tchoshanov, M. A. (2001). The Role of Representation(s) in Developing Mathematical Understanding. Theory into practice, 40(2), 118-127.

Pehkonen, E., Ahtee, M., Tikkanen, P., \& Laine, A. (2011). Pupils' conceptions on mathematics lessons revealed via their drawings. In B.Rösken \& M. Casper (Eds.), Current State of Research on Mathematical Beliefs XVII. Proceedings of the MAVI-17 Conference (pp. 182-191). University of Bochum.

Pehkonen, E., Ahtee, M., \& Laine, A. (2016). Pupils' drawings as a research tool in mathematical problemsolving lessons. In P. Felmer, E. Pehkonen, \& J. Kilpatrick (Eds.), Posing and solving mathematical problems: Advances and new perspectives (Research in mathematics education) (pp. 167-188). Cham, Switzerland: Springer.

Picker, S., \& Berry, J., (2000). Investigating pupils' images of mathematicians. Educational Studies in Mathematics, $43,65-94$.

Pietsch, M., \& Tulowitzki, P. (2017). Disentangling school leadership and its ties to instructional practices an empirical comparison of various leadership styles. School Effectiveness and School Improvement, 28(4), 629-649.

Remesal, A. (2009). Accessing primary pupils' conceptions of daily classroom assessment practices. In D. M. McInerney, G. T. L. Brown, \& G. A. D. Liem (Eds.), Students perspectives on assessment: What students can tell us about assessment for learning (pp. 25-51). Charlotte, NC: Information age publishing, Inc.

Robinson, V. M. J. (2007). The impact of leadership on student outcomes: Making sense of the evidence. https://research. acer.edu.au/research_conference_2007/5

Rock, D., \& Shaw, J. M. (2000). Exploring children's thinking about mathematicians and their work. Teaching Children Mathematics, 6(9), 550-555.

Roesken, B., Pepin, B., \& Toerner, G. (2011). Beliefs and beyond: Affect and the teaching and learning of mathematics. ZDM, 43(4), 451-455.

Schroeder, T. L., \& Lester Jr., F. K. (1989). Developing understanding in mathematics via problem solving. In P. R. Trafton \& A. P. Shulte (Eds.), New Directions for Elementary School Mathematics (pp. 31-42). Reston, VA: NCTM.

Science and Technology Policy Division of the OECD Directorate for Science, Technology and Innovation. (2016). Policy profiles (OECD STI Outlook 2016). Retrieved from https://www.innovationpolicyplatform. org/content/policy-profiles-oecd-sti-outlook-2016

Smetana, L. K., Wenner, J., Settlage, J., \& McCoach, D. B. (2016). Clarifying and capturing "trust" in relation to science education: dimensions of trustworthiness within schools and associations with equitable student achievement. Science Education, 100(1), 78-95.

Srikoom, W., Faikhamta, C., \& Hanuscin, D. L. (2018). Dimensions of effective STEM integrated teaching practice. K-12 STEM Education, 4(2), 313-330.

Stohlmann, M., Moore, T., \& Roehrig, G. (2012). Considerations for teaching integrated STEM education. Journal of Pre-College Engineering Education Research, 2(1), 28-34.

Sullivan, P. (2011). Teaching mathematics: Using research-informed strategies. Camberwell, VIC: Australian Council for Educational Research.

Thomas, J. A., Pedersen, J. E., \& Finson, K. (2001). Validating the Draw-A-Science-Teacher-Test Checklist: Exploring mental models and teacher beliefs. Journal of Science Teacher Education, 12(4), 295-310.

Timms, M., Moyle, K., Weldon, P., \& Mitchell, P. (2018). Challenges in STEM learning in Australian schools. Policy Insights, Issue 7. Camberwell, VIC: ACER.

Tulowitzki, P. (2019). Supporting instructional leadership and school improvement? reflections on school supervision from a German perspective. Journal of Educational Administration, 57(5), 571-581.

Utley, J., \& Showalter, B. (2007). Preservice elementary teachers' visual images of themselves as mathematics teachers. Focus on Learning Problems in Mathematics, 29(3), 1-14.

Vasquez, J., Sneider, C., \& Comer, M. (2013). STEM lesson essentials, grades 3-8: Integrating science, technology, engineering, and mathematics. Portsmouth, NH: Heinemann.

Wienk, M. (2017). Discipline profile of the mathematical sciences. Retrieved from https://amsi.org.au/wpcontent/ uploads/2017/10/discipline-profile-2017-web.pdf

Zubrowski, B. (2002). Integrating science into design technology projects: Using a standard model in the design process. Journal of Technology Education, 13(2), 48-67. 